\title{
High Enthalpy Studies of Capsule Heating in an Expansion Tunnel Facility
}

\author{
Aaron Dufrene* \\ Matthew MacLean ${ }^{\dagger}$ \\ Michael Holden ${ }^{\ddagger}$ \\ CUBRC / LENS, Buffalo, NY, 14225
}

\begin{abstract}
Measurements were made on an Orion heat shield model to demonstrate the capability of the new LENS-XX expansion tunnel facility to make high quality measurements of heat transfer distributions at flow velocities from $3 \mathrm{~km} / \mathrm{s}\left(\mathrm{h}_{0}=5 \mathrm{MJ} / \mathrm{kg}\right)$ to $8.4 \mathrm{~km} / \mathrm{s}\left(\mathrm{h}_{0}=\right.$ $36 \mathrm{MJ} / \mathrm{kg}$ ). Thirty-nine heat transfer gauges, including both thin-film and thermocouple instruments, as well as four pressure gauges, and high-speed Schlieren were used to assess the aerothermal environment on the capsule heat shield. Only results from laminar boundary layer runs are reported. A major finding of this test series is that the highenthalpy, low-density flows displayed surface heating behavior that is observed to be consistent with some finite-rate recombination process occurring on the surface of the model. It is too early to speculate on the nature of the mechanism, but the response of the gages on the surface seems generally repeatable and consistent for a range of conditions. This result is an important milestone in developing and proving a capability to make measurements in a ground test environment and extrapolate them to flight for conditions with extreme non-equilibrium effects. Additionally, no significant, isolated stagnation point augmentation ("bump") was observed in the tests in this facility. Cases at higher Reynolds number seemed to show the greatest amount of overall increase in heating on the windward side of the model, which may in part be due to small-scale particulate.
\end{abstract}

\section{Introduction}

T ENS XX expansion tunnel facility, shown in Fig. 1, is a unique facility that has been designed and built over the $\downarrow$ past several years specifically to provide the environment that duplicates the conditions of atmospheric reentry by replicating the extreme energy levels of orbital and super-orbital velocities while maintaining a clean, quiescent thermochemical state in the freestream test gas. In most other types of high-enthalpy facilities, a stagnant reservoir of gas is heated by one of several means to a very high total temperature and then expanded through a convergingdiverging nozzle to accelerate the gas. At sufficiently high enthalpies (above $4 \mathrm{MJ} / \mathrm{kg}$ for air), the test gas dissociates in the reservoir; the subsequent, rapid expansion through the nozzle freezes non-equilibrium thermal and chemical energy in the freestream test gas. An expansion tunnel is different in that the bulk of the energy is added to the test gas by unsteady expansion, so the kinetic energy of the gas in increased while the temperature of the gas remains relatively low. A secondary benefit of this type of facility is that it can be used to generate very high Reynolds number flows since the flow is never stagnated and the low-pressure moving gas can have incredibly high effective stagnation pressure.

\footnotetext{
* Senior Research Scientist, Member AIAA; dufrene@cubrc.org

† Senior Research Scientist, Member AIAA; maclean@cubrc.org

‡ Vice President of Hypersonics, Fellow AIAA; holden@cubrc.org
} 


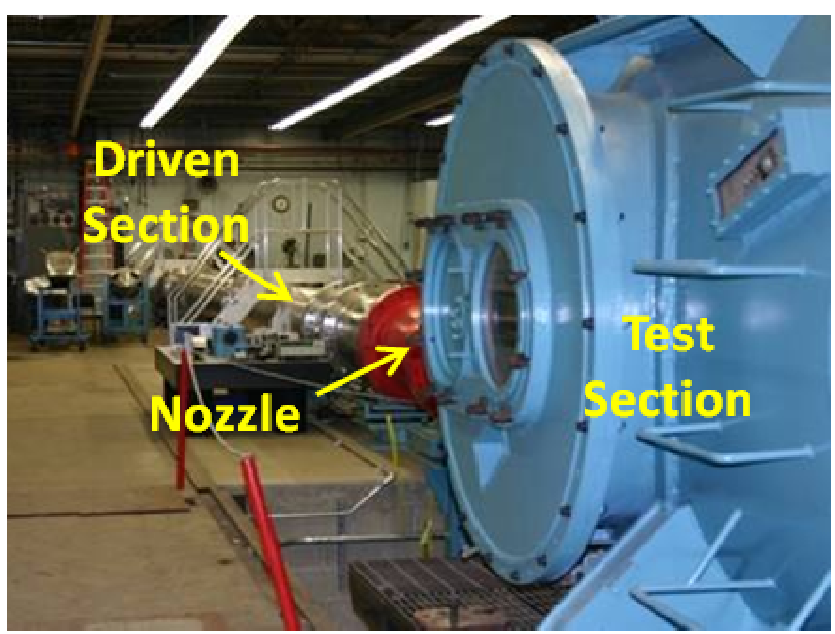

Figure 1. LENS-XX - 61- cm. large-scale expansion tunnel at CUBRC

\section{A. LENS-XX Facility Description}

The LENS-XX expansion tunnel facility generates test flows in a manner that is very different from the reflected shock tunnel facilities. Reflected shock tunnels operate by driving strong incident and reflected shocks through the test gas which results in a high pressure, high temperature, stagnant reservoir which can be expanded through a converging-diverging nozzle like a blowdown facility. Expansion tunnels do not stagnate the test gas at any time before it flows over the test article. Instead, the test gas is set into motion by a single shock of only weak to moderate strength, and the bulk of the energy in the flow is added to kinetic energy directly by using an unsteady acceleration to increase the velocity. A wave diagram of the basic states of the expansion tunnel is given in Fig. 2. In this figure, position is plotted schematically along the horizontal axis and time is plotted qualitatively along the vertical axis. The three test chambers are filled to different pressures and initially separated by diaphragms, where the primary diaphragm between the driver and test gas sections is broken at a time designated as zero. The waves in the diagram are shocks (red), contact surfaces (dotted grey) or isentropic expansion fans (green), where the thermodynamic state and/or composition of the gases change across any of the waves. Important thermodynamic states of the gases are numbered and the label is colored by the gas composition.

The driver gas (State 4) is a very high pressure, heated, low molecular weight gas (typically hydrogen or helium) that causes a primary shock of moderate strength to move through the test gas when the primary diaphragm is broken. This shock raises the pressure in the test gas just sufficiently to break the secondary diaphragm and causes an initial velocity toward the right in the schematic (State 2). The peak temperature of the test gas during the entire excitation process occurs at State 2, which is typically on the order of 2,000-3,000 K or approximately an order of magnitude lower than a comparable freestream condition in a reflected shock tunnel. The moving test gas then accelerates into a much lower pressure acceleration segment that is typically at nearly vacuum (State 10). The unsteady expansion causes the test gas to cool and accelerate to very high velocities, given by State 5 . This is the freestream state of the test gas at the end of the tube. The freestream velocity obtained is primarily dependent on the molecular weight of the driver gas, the pressure of the driver gas, and the vacuum level of the acceleration segment. Test time available for testing begins at the contact surface between States 20 and 5 and lasts until either the tail of the left-running expansion between States 2 and 5 reaches the test station or until the reflected head of the same wave reaches the test station.[1] The freestream state of the gas typically has a translational temperature near $300 \mathrm{~K}$ with a very high velocity. The relative strengths of the primary shock (State 1 to State 2) and the unsteady expansion (State 2 to State 5) can be utilized to generate different Mach numbers and test conditions for a given total pressure ratio $\left(P_{4} / P_{10}\right)$ which provides a significant degree of flexibility for the facility. Additional details about the LENS$\mathrm{XX}$ facility may be found in the work of Dufrene, et al.[2, 3]

Determination of test conditions for this facility uses the CHEETAh code discussed by MacLean, et al.[4] This code solves for the intermediate states of the primary and secondary wave systems shown in Fig. 2 incorporating equilibrium chemistry, ionization, and thermodynamic excitation mechanisms. This tool provides a simple and accurate way to determine the State 5 condition using measured data from the facility for each run. One, two, and three-dimensional simulations of the expanding gas in the 96" test section have been performed, but describing the 
turbulent boundary layer growth in the acceleration tube is a major uncertainty in such calculations. We have found that measuring the Pitot pressure immediately next to or on the test article provides an additional anchor for the CHEETAh code to most accurately determine the freestream state of the expanded gas.

The expansion tube concept is not new,[5] but the LENS-XX facility is unique in its large size and development as both a research facility and a production wind tunnel. The LENS-XX facility offers four unique advantages that no other facility in the world can offer. The first is a long test time, which will be on the order of one millisecond for most conditions and up to eight milliseconds for very low enthalpy flows (most other expansion tubes measure test time in tens of microseconds). Long test times have several advantages such as improved signal-to-noise for spectral, visual, or integrated measurements, time to stabilize separated regions, subsonic regions, or wakes, and improved data filtering options for measurements such as heat transfer or forces and moments. Second, the LENSXX facility is unique in that it employs a moderately heated hydrogen driver and emission comes only from the shock layer. Other high enthalpy facilities use piston driven, arc heated, or combustion drivers[6-8] which are often as hot as the shock-layer gas itself so a spectrometer at the stagnation point of a model will be unable to distinguish between the emission that it sees from the shock layer and that from the driver. Third, the large size of the facility provides a very large inviscid core flow to test models either in the 60-cm (24") tube test section or the larger 240cm (96”) test section. Finally, we test our models out of the line-of-sight of the expansion tube. This is critical because extensive damage can occur from the metal diaphragms used in the driver; most other facilities cannot employ the sensitive and accurate measurement techniques that CUBRC utilizes without sacrificing the model on each and every run.

Notional maps of the duplication capability of the LENS-XX facility for air and carbon dioxide test gases are shown in Fig. 3(a) and (b). In each case, several trajectories of interest from recent NASA exploration activities are shown for reference to demonstrate that LENS-XX can duplicate an interesting range of conditions. In general, the facility can run any mixture of test gases; here, air was used with the exception of one run with pure nitrogen.

Although the facility is relatively new, calibration and validation of the facility for flows of interest has been ongoing since late 2010. This calibration process made basic characterization measurements such as profiles of Pitot pressure in the test section plane as well as measurements on building-block models such as wedge, hemisphere, and cylinder shapes along with comparisons to CFD using freestream conditions determined using the techniques outlined by MacLean, et al. [4]

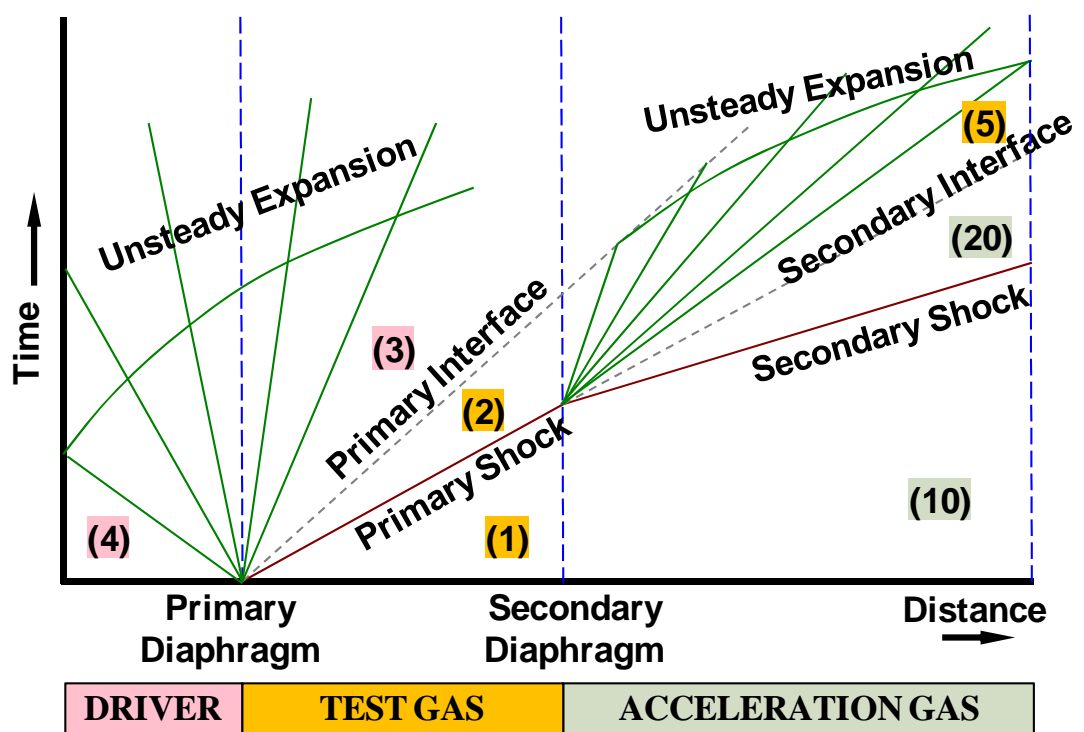

Figure 2. X-t Wave Diagram of an Expansion Tunnel 


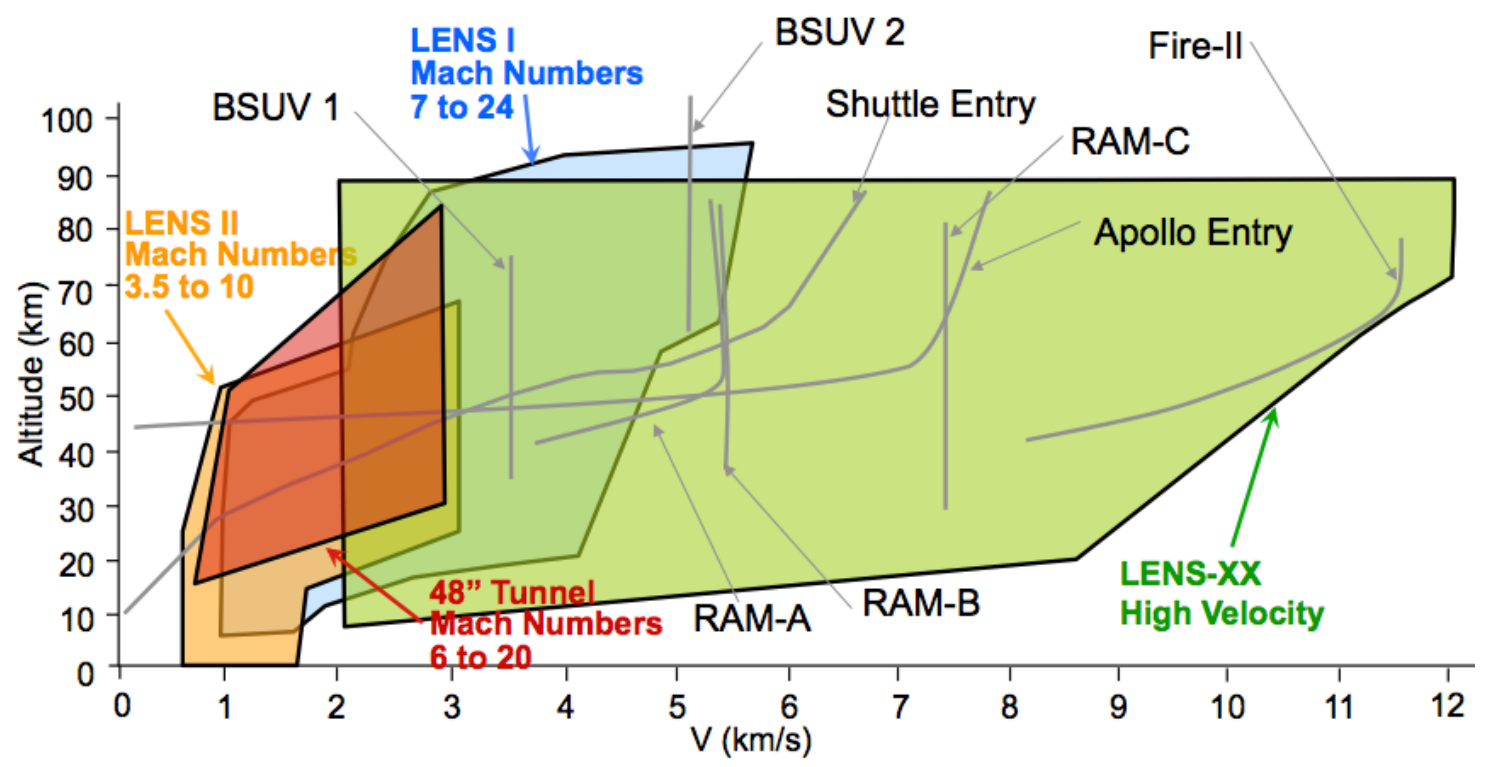

(a) air (Earth entry)

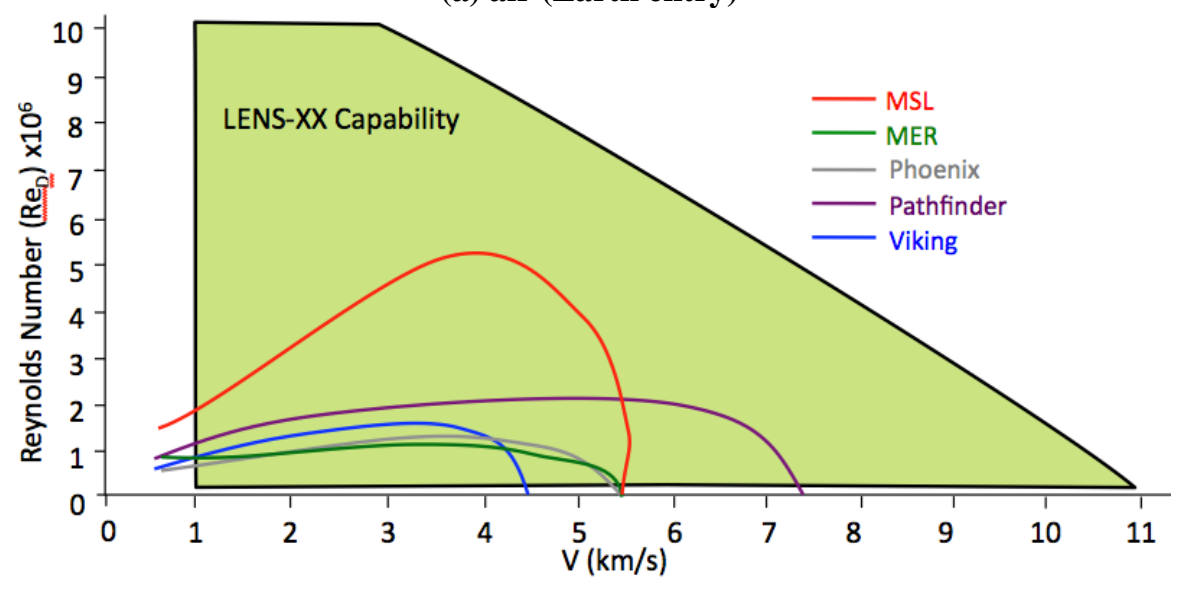

(b) $\mathrm{CO}_{2}$ (Mars/Venus entry)

Figure 3. Capability of LENS-XX Facility to Duplicate Hypersonic Conditions in Air and $\mathrm{CO}_{2}$

\section{B. Instrumentation and Diagnostics}

A 7-in. diameter Orion heat shield model was designed for testing in the LENS-XX facility. A schematic of the instrumentation layout is shown in Fig. 4.There were a total of 13 thin-film heat transfer gauges, 26 coaxial medtherm gauges, and 4 piezoelectric pressure transducers used to capture data on the heat shield surface. The origin is located at the center of the heat shield surface, with the negative $x$ direction pointing towards the apex and the heat flux gauges evenly spaced along the $z$-axis. Pressure gauges are offset from the $z$-axis in the negative $y$ direction and also evenly spaced with P1 nearest the stagnation point. Figure 5 shows a picture of the instrumented model ready for testing. The model was mounted in the facility using an adapter that set the angle of attack of the heat shield to $20^{\circ}$. This attitude places the stagnation point of the heat shield at approximately $\mathrm{z}=+2.4 \mathrm{in} .(+6.1 \mathrm{~cm})$, which corresponds most closely with gauge T6. 

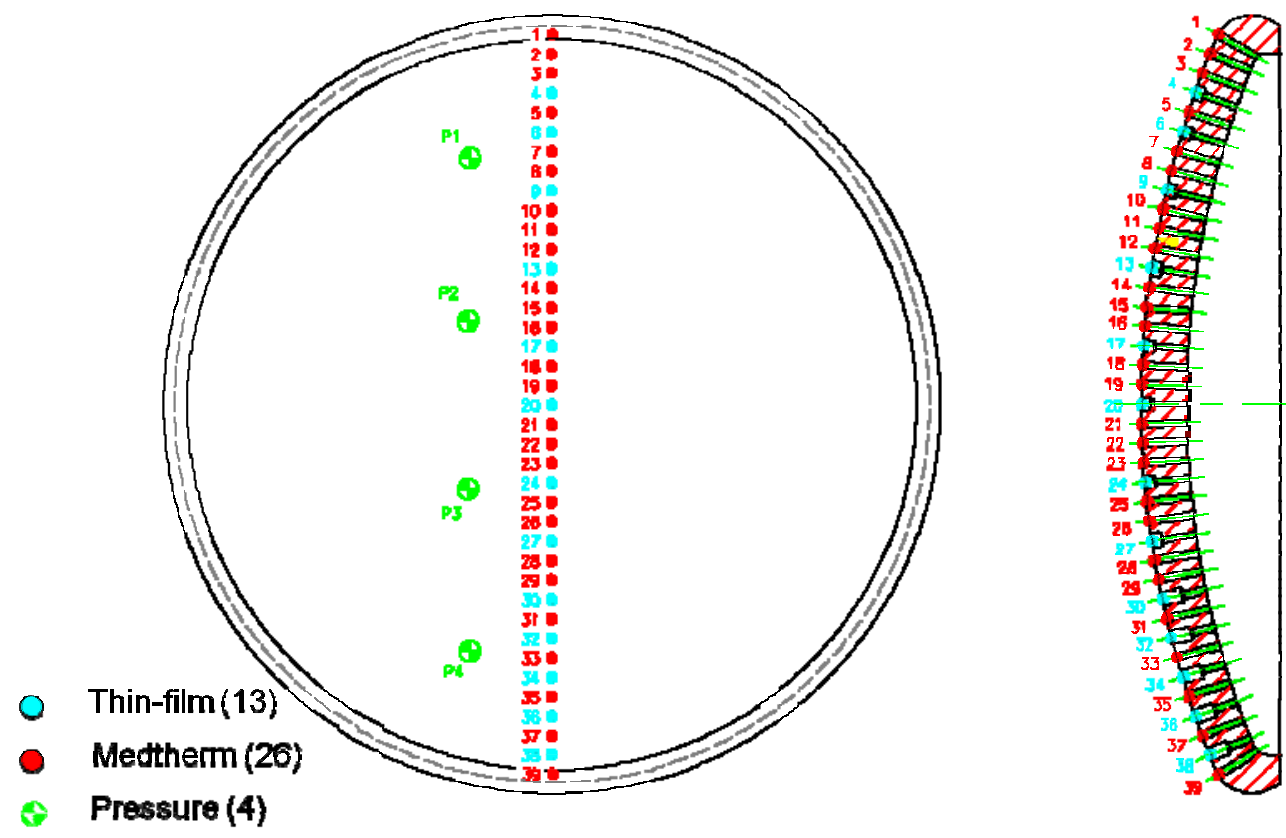

Figure 4. 7 in. Diameter Spherical Capsule Instrumentation Layout

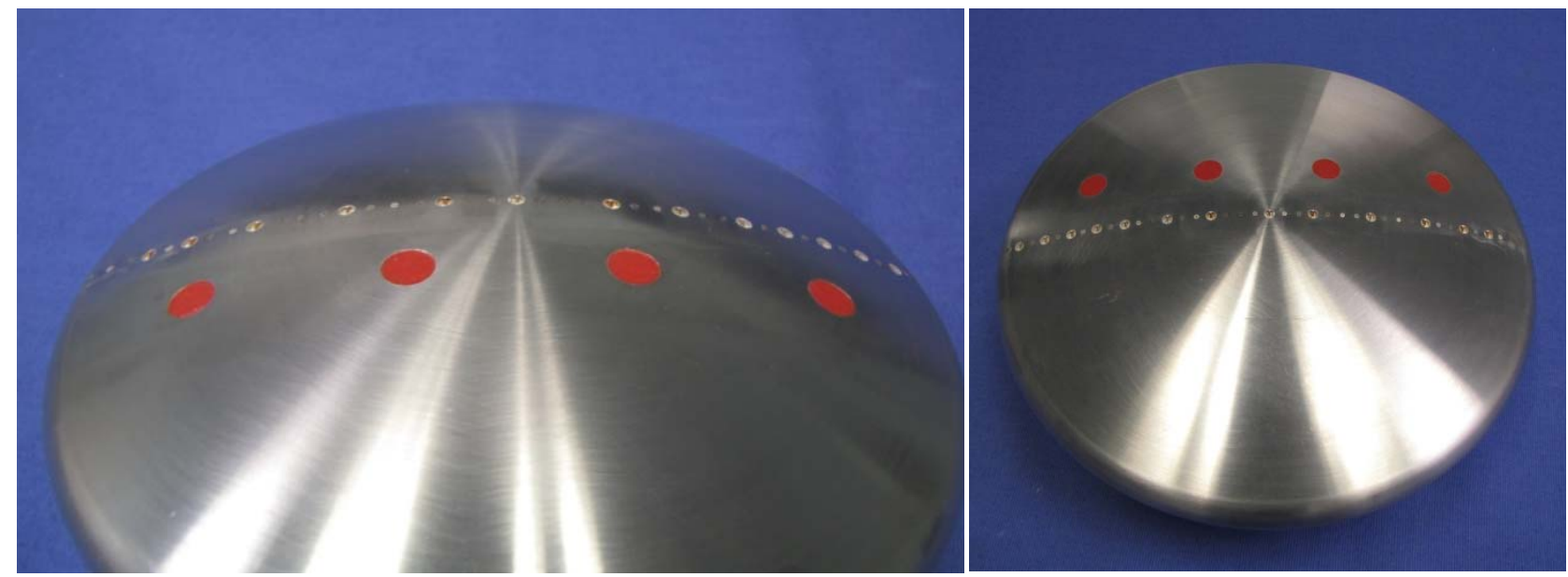

Figure 5. Instrumented Capsule Model Prior to Testing

\section{Test Results}

\section{A. Experimental Test Program}

In the 91-CH program, measurements were made on a 7 in. diameter Orion heat shield model to demonstrate the capability of the new LENS-XX expansion tunnel facility to make quality heat transfer distributions at flow velocity levels from $3 \mathrm{~km} / \mathrm{s}\left(\mathrm{h}_{0}=5 \mathrm{MJ} / \mathrm{kg}\right)$ to $8.4 \mathrm{~km} / \mathrm{s}\left(\mathrm{h}_{0}=36 \mathrm{MJ} / \mathrm{kg}\right)$. Laminar run data from six runs are presented ranging from $12 \mathrm{MJ} / \mathrm{kg}$ to $36 \mathrm{MJ} / \mathrm{kg}$. These runs were used to study the heating distribution on the Orion heat shield across a large enthalpy range, including one repeat run (Runs 3 and 6). The test matrix is shown in Table I. Run 2 was essentially a repeat of Run 1 a well, but used air as the test gas instead of nitrogen. Photographs of the model installed in LENS-XX prior to testing are shown in Fig. 6. Detailed results of the six model runs are discussed in the following subsections. 
Table I. Test Matrix

\begin{tabular}{|c|c|c|c|c|c|c|c|c|c|c|}
\hline Run & Gas & $\begin{array}{c}\text { ho } \\
(\mathrm{MJ} / \mathrm{kg})\end{array}$ & M & $\underset{(\mathrm{km} / \mathrm{s})}{U}$ & $\begin{array}{c}P \\
(\mathrm{~Pa})\end{array}$ & $\begin{array}{c}T \\
(K)\end{array}$ & $\begin{array}{c}\rho \\
\left(\mathrm{kg} / \mathrm{m}^{3}\right)\end{array}$ & $\begin{array}{c}A O A \\
\left({ }^{\circ}\right)\end{array}$ & $\begin{array}{l}\text { ReD } \\
\times 10^{6}\end{array}$ & Notes \\
\hline 1 & $\mathrm{~N}_{2}$ & 17.9 & 14.2 & 5.92 & 95 & 422 & .000761 & 20 & 0.04 & \\
\hline 2 & Air & 17.6 & 13.3 & 5.85 & 128 & 488 & .000907 & 20 & 0.04 & Repeat of Run 1 w/ Air \\
\hline 3 & Air & 25.1 & 12.4 & 6.97 & 52 & 812 & .000222 & 20 & 0.01 & \\
\hline 5 & Air & 12.0 & 14.2 & 4.83 & 203 & 288 & .00245 & 20 & 0.12 & \\
\hline 6 & Air & 25.3 & 12.5 & 7.00 & 56 & 813 & .000241 & 20 & 0.01 & Repeat of Run 3 \\
\hline 13 & Air & 36.4 & 11.4 & 8.35 & 132 & 1416 & .000323 & 20 & 0.009 & \\
\hline
\end{tabular}

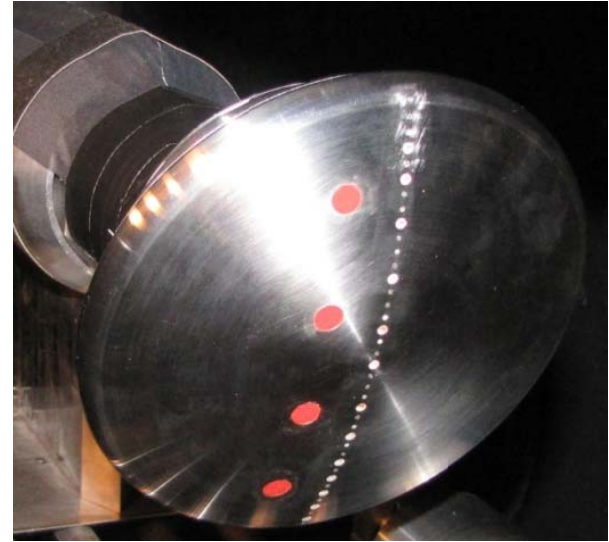

(a) close-up of model prior to testing

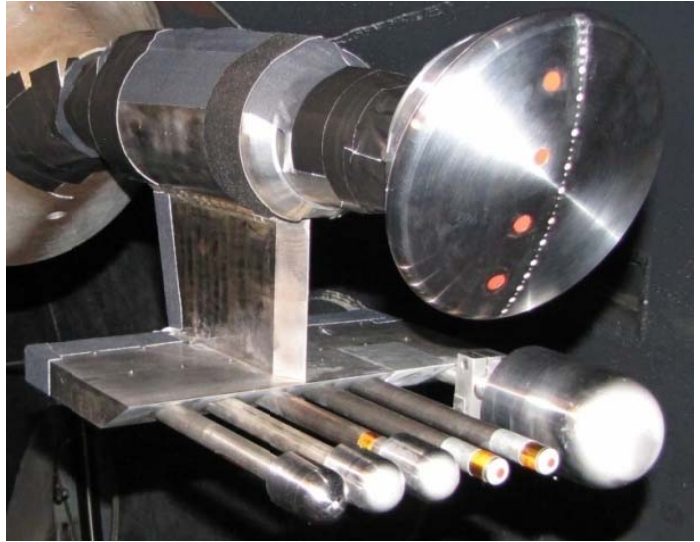

(b) model with calibration rake

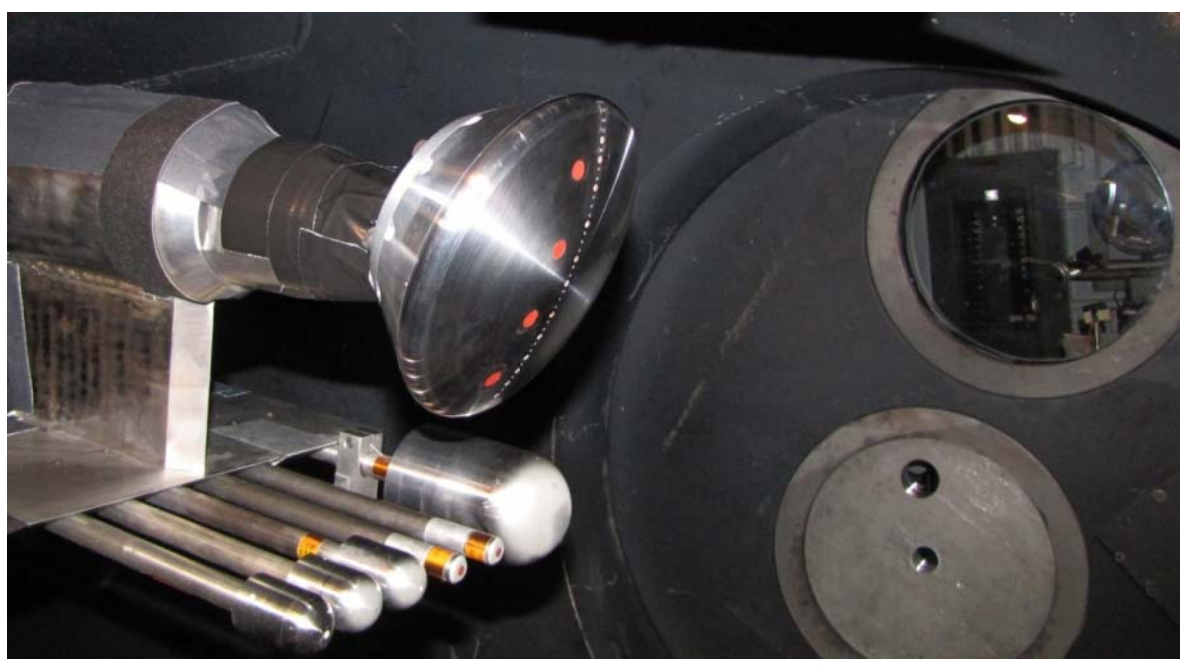

(c) installed model and rake including 16" Schlieren windows

Figure 6. Pre-Test Photos of Capsule Model Installed in LENS-XX 


\section{B. Determination of Test Condition}

Test conditions for each run in the LENS-XX facility are computed using the CHEETAh code outlined by MacLean, et al. [4] CHEETAh solves the primary and secondary wave systems shown in Fig. 2 by incorporating options for equilibrium chemistry and thermodynamics. This code makes use of measured operating parameters in the facility to anchor the calculation of freestream conditions. In the primary system (consisting of States 1, 2, 3, 4), the initial test gas state (State 1), the driver gas temperature (State 4), and the primary shock speed are measured quantities. The effective driver gas pressure is computed to account for pressure losses incurred by non-ideal breaking of the large, steel diaphragms. In the secondary system (consisting of States 2, 5, 20, 10), the computed test gas state (State 2), the acceleration gas temperature (State 10), and the secondary shock speed are measured quantities. The effective acceleration gas pressure is calculated to account for the difficulty in making very accurate measurements of vacuum level pressures.

Non-ideal secondary diaphragm breaking is also an important issue in expansion tunnels. This effect can be accounted for by defining a State 2s, which modifies State 2 through a traveling wave at the point of secondary diaphragm break. CHEETAh can account for this effect empirically by specifying measured pressures located on the wall of the facility just upstream and just downstream of the secondary diaphragm. Conditions that use little Mylar at this station tend to break in a nearly ideal fashion while conditions with thick Mylar tend to show a correction.

The expansion process in the test section is anchored with a measured Pitot pressure at or near the location of the model. The effective area ratio of the expanding nozzle is different from the geometric area ratio of the nozzle because of viscous boundary layer growth both on the expansion tube walls and the surface of the nozzle itself, which are extremely difficult to accurately characterize.

\section{Description of Numerical Tools}

The primary, production computational fluid dynamics (CFD) tool used for LENS facility design, design-ofexperiment, and data validation is the Data-Parallel Line-Relaxation (DPLR) code licensed by NASA Ames Research Center (ARC). DPLR is a multi-block, structured, finite-volume code that solves the reacting NavierStokes equations including finite rate chemical and thermal non-equilibrium effects. This code is based on the dataparallel line relaxation method[9] and implements a modified (low dissipation) Steger-Warming flux splitting approach[10] for the convection terms and central differencing for the diffusion terms. For the set of calculations shown in this work, standard five $\left(\mathrm{N}_{2}, \mathrm{O}_{2}, \mathrm{NO}, \mathrm{N}, \mathrm{O}\right)$ and seven $\left(\mathrm{N}_{2}, \mathrm{O}_{2}, \mathrm{NO}, \mathrm{N}, \mathrm{O}, \mathrm{NO}^{+}\right.$, e $)$species air models were used with dissociation reaction rates given by Park, et al.[11] and Zel'Dovich reaction rates given by Bose and Candler.[12, 13] Reverse reaction rates were computed from equilibrium. Finite rate vibrational relaxation is modeled via a simple harmonic oscillator vibrational degree of freedom[14] using the Landau-Teller model.[15] Vibrational energy relaxation rates are computed by default from the semi-empirical expression due to Millikan and White,[16] but rates from the work of Camac[17] and Park, et al.[18] are substituted for specific collisions where experimental data exists. Vibration-dissociation coupling is currently modeled using the $T$ - $T v$ approach of Park[19] or with some preliminary implementation of coupled vibration-dissociation vibration (CVDV) coupling.[20] Transport properties for the reacting mixtures are modeled in DPLR for high enthalpy flow[21, 22] using the binary collision-integral based mixing rules from Gupta, et al.[23] with a database of relevant collision integral data for high temperature air collisions.[24] Diffusion coefficients are modeled using the self-consistent effective binary diffusion (SCEBD). [25] Turbulence models available in the DPLR code currently include the Baldwin-Lomax 0equation model,[26] the Spalart-Allmaras model 1-equation model,[27] and the Shear Stress Transport (SST) 2equation model[28] each with corrections for compressibility effects.[29, 30]

The DPLR code has several options available to model surface catalysis at the solid surface boundary. Boundary conditions for each reacting species are individually computed from species mass balance at the surface, where species diffusion balances catalytic production for a non-ablating wall and a self-consistent diffusion model enforces total mixture diffusion flux conservation. The non-catalytic wall boundary condition enforces zero catalytic production for each species, which implies that diffusion flux for each will be zero. In this work, the "supercatalytic" boundary condition sets a mixture composition explicitly at the surface that coincides with the lowest energy composition of the gas without regard for reaction kinetics or reactant availability. The super-catalytic boundary condition enforces a non-physical set of catalytic production rates at the surface, but does provide an upper limit on energy release at the surface and thus a conservative estimate of heat transfer rate. The specified reaction efficiency (SRE) model enforces a user-specified efficiency for homogeneous catalytic reactions based on the fraction of reactant species that reach the surface for which a recombination event occurs. The reaction 
efficiency (or reactant loss efficiency), $\gamma$, may be specified as constant or as a function of temperature resulting from empirical curve-fit of experimental data. Very recently, a generalized, physics-based finite rate surface chemistry (FRSC) model[31, 32] has been implemented in the DPLR code that allows for an arbitrary number of physical reaction forms such as Eley-Rideal and Langmuir-Hinshelwood recombination events to be specified. Gas phase reactants interact with adsorbed surface and bulk (thermal protection system) species through physical processes that can be used to model both catalytic and ablation systems.

\section{Experimental Data Comparisons to CFD}

The experimental measurements of surface heat transfer rate, surface pressure, and shock profile for each experiment have been compared to simulations performed with the DPLR code. Each simulation was performed on a four-block three-dimensional grid consisting of a total $1.6 \times 10^{6}$ hexagonal cells. For each individual simulation, the grid was adapted to the bow shock to mitigate numerical disruption of heat transfer prediction and the near wall cell center was clustered to a cell Reynolds number less than one with approximately 5\% stretching ratio. In all the experiments shown in this work, the character of the experimental data is laminar, so fully laminar simulations were performed. Radiative heating has been neglected in all the simulations; it is unlikely to be significant except perhaps for Run 13. In all cases, the surface data measured in the experiments have been plotted with plus and minus one standard deviation bars on each data point.

No Schlieren photograph was available for Run 13, but it was taken on each of the other runs. These images were compared to the CFD solution by extracting the magnitude of the density gradient along the centerplane of each CFD solution and adjusting the coloring scheme until only the bow shock and the boundary layer were clearly visible. In each case, the corresponding CFD solution was overlaid on the experimental tare image by using a digital image manipulation software package since the density gradient in the boundary layer is very large and can obscure the true surface in the experimental images with flow on. These comparisons are presented in Figs. 7 - 11. Each figure presents the comparison for a single run. In each figure, (a) presents the experimental Schlieren image taken during the middle of the averaging interval, (b) presents the corresponding CFD solution overlaid on the tare image (no flow), and (c) presents the CFD solution overlaid on the image with flow. In many cases, the comparison between CFD and experiment is so good that it the CFD solution covers up the shocks otherwise visible in the Schlieren image. Although it does not seem possible to make a quantitative statement about the accuracy between the CFD and the experiment because of the qualitative process by which we have aligned the two images, there is no clear evidence that the CFD does not match the experiments sufficiently well. In contrast, several observations have been previously made in the LENS-I reflected shock tunnel in high-enthalpy reacting air and carbon dioxide test gases where macroscopic discrepancies were clearly visible using this comparison technique.[33, 34]

The comparison of the measured and predicted surface pressure for all six runs is shown in Fig. 12. In general the surface pressure is predicted accurately. In some early runs, the pressure transducer nearest to the stagnation point was not operating and had to be replaced several runs into the test program. It is emphasized that these four pressure measurements are slightly off the centerplane of the test article. The corresponding solution plane has been extracted to make the CFD comparison, but we note that the pressure level is only a few percent different from the corresponding centerplane distribution anyway.

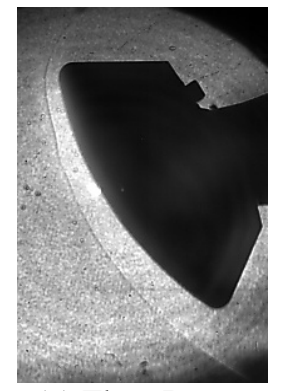

(a) Flow Image

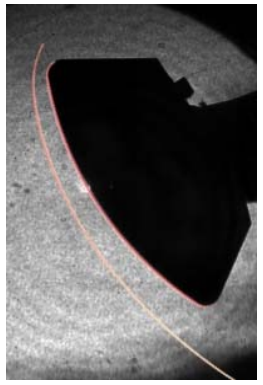

(b) CFD and Tare

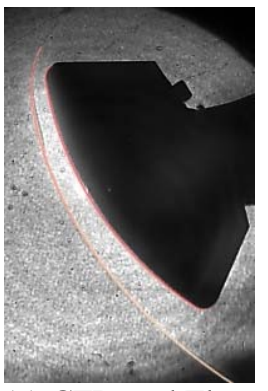

(c) CFD and Flow

Figure 7. Comparison of Experimental Schlieren and CFD Density Gradient Magnitude for Run 01 


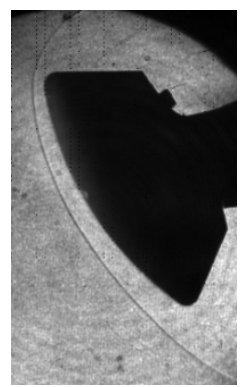

(a) Flow Image

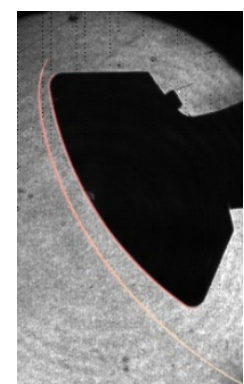

(b) CFD and Tare

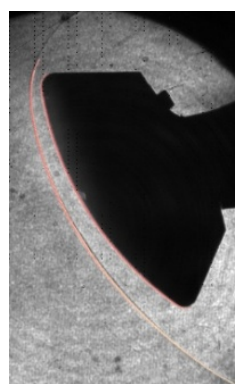

(c) CFD and Flow

Figure 8. Comparison of Experimental Schlieren and CFD Density Gradient Magnitude for Run 02

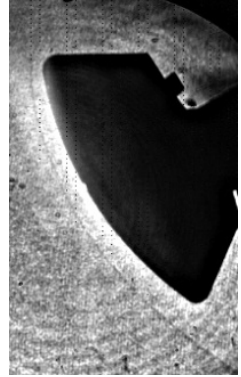

(a) Flow Image

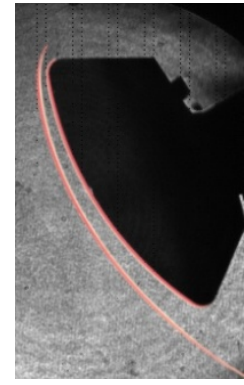

(b) CFD and Tare

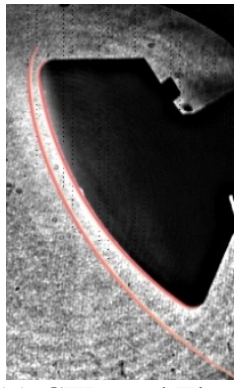

(c) CFD and Flow

Figure 9. Comparison of Experimental Schlieren and CFD Density Gradient Magnitude for Run 03

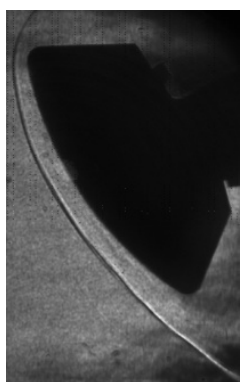

(a) Flow Image

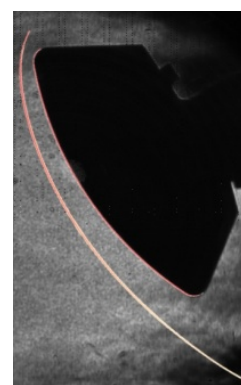

(b) CFD and Tare

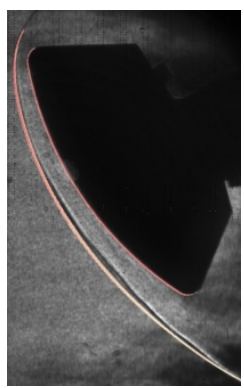

(c) CFD and Flow

Figure 10. Comparison of Experimental Schlieren and CFD Density Gradient Magnitude for Run 05

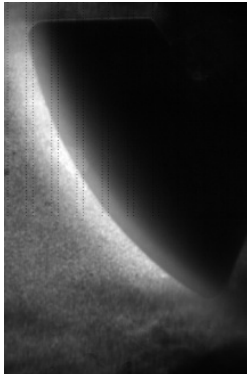

(a) Flow Image

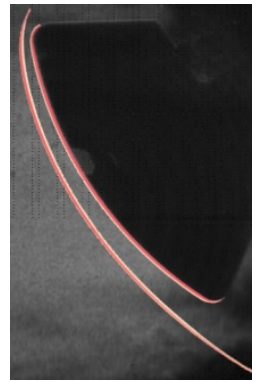

(b) CFD and Tare

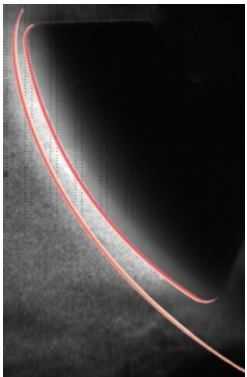

(c) CFD and Flow

Figure 11. Comparison of Experimental Schlieren and CFD Density Gradient Magnitude for Run 06 


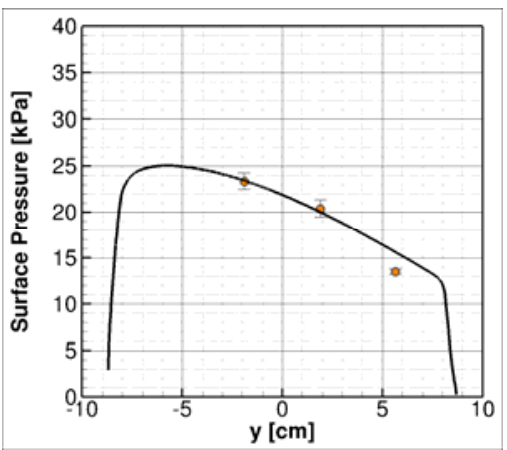

(a) Run 01

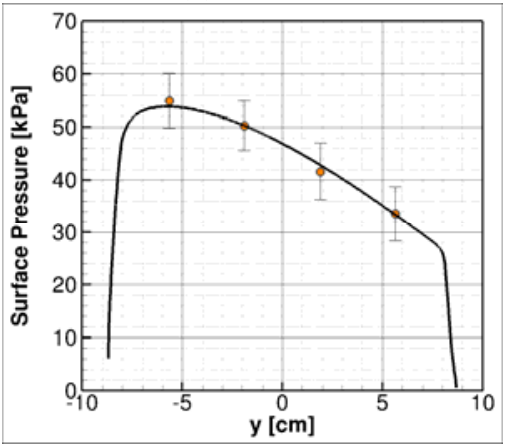

(d) Run 05

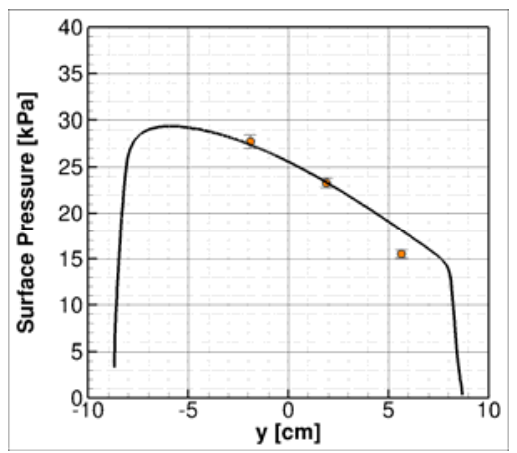

(b) Run 02

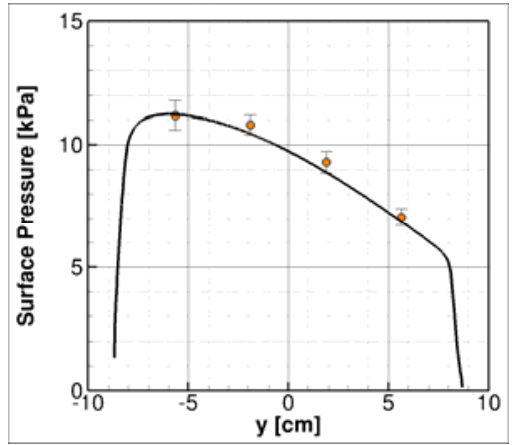

(e) Run 06

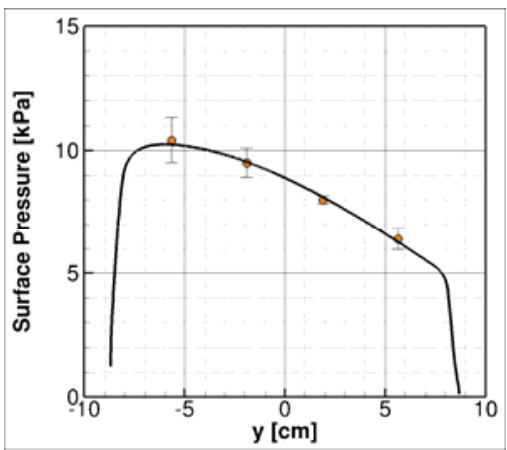

(c) Run 03

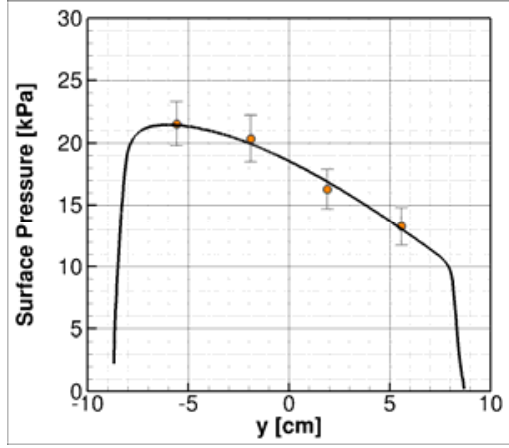

(f) Run 13

Figure 12. Comparison of Measured and Predicted Surface Pressure for All Runs

Finally, the surface heat flux comparisons are shown for all six runs in Fig. 13. In this case a number of CFD solutions are shown with different surface catalysis boundary condition models. The non-catalytic and supercatalytic solutions essentially act to demonstrate the limiting bounds of predicted heat flux from the CFD code. In general, the data lies between these two limits. A number of solutions have been run with the SRE model and different assumed recombination efficiencies have also been shown, with the solution assuming $\gamma=0.02$ seeming to best fit the general data level overall, which is very consistent with earlier findings on cylindrical and hemispherical probe shapes.[35] A few observations can be made about the heat transfer comparisons. First, analysis of the CFD solutions shows that the effect of SRE catalytic reactions is primary on oxygen recombination as there are very few nitrogen atoms reaching the surface, particularly at the lower enthalpy levels. Second, the SRE model considers only homogeneous recombination (e.g. $\mathrm{O}+\mathrm{O} \rightarrow \mathrm{O}_{2}$ and $\mathrm{N}+\mathrm{N} \rightarrow \mathrm{N}_{2}$ reactions), so the surface is considered inert to nitric oxide. A previous study from LENS-XX looking at cylindrical and hemispherical shapes did look at the effect of nitric oxide reactivity and found that it can lower the predicted heat transfer rate by several percent. This effect was not considered here because the results are expected to be similar. Additionally, gas phase modeling such as transport coefficients and gaseous reaction rates can influence the predicted heat transfer. These effects were also considered in our previous work. Here, we emphasize that the conclusion that the experimental data best matches the CFD with a SRE boundary condition using $\gamma=0.02$ is contingent upon use of all of these associated models. Finally, in general, we do not observe any notable differences between the thin-film and the coaxial thermocouple heat flux sensors. 


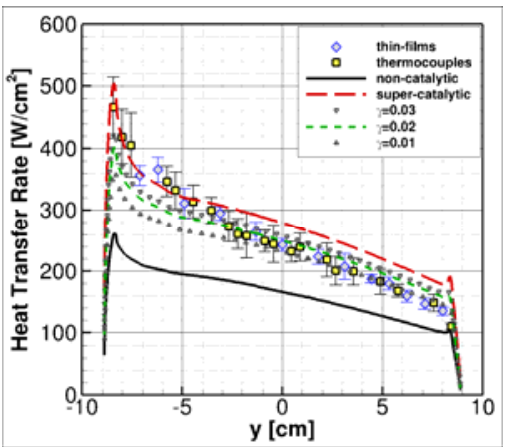

(a) Run 01

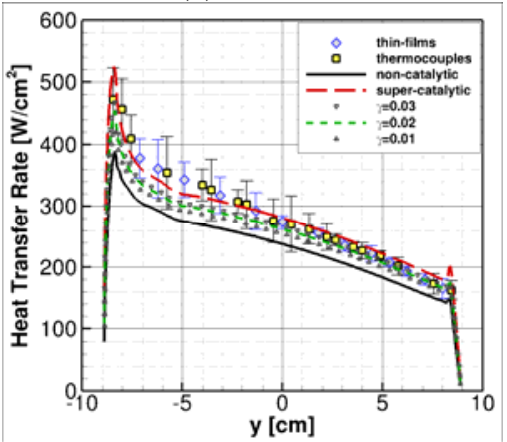

(d) Run 05

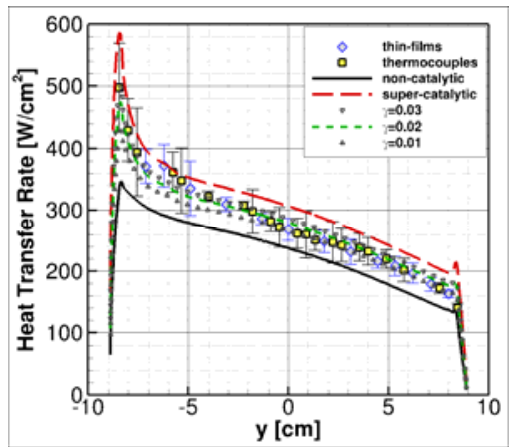

(b) Run 02

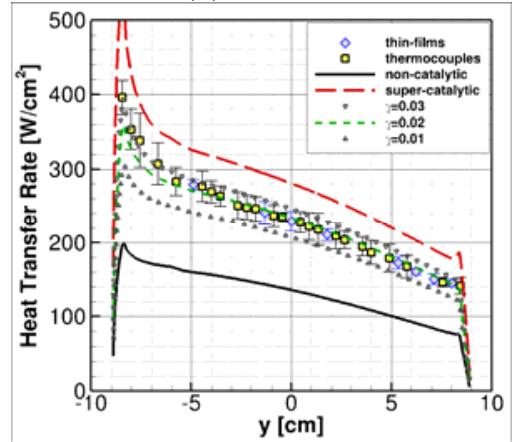

(e) Run 06

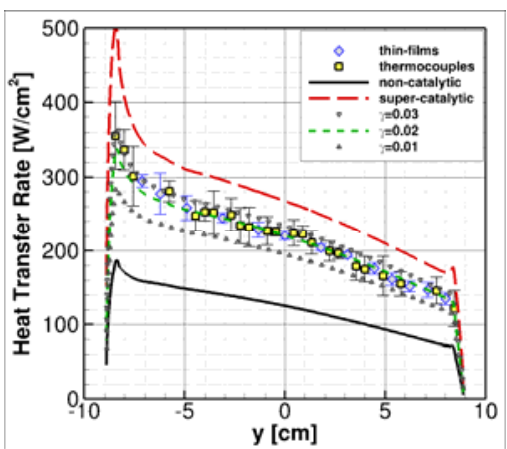

(c) Run 03

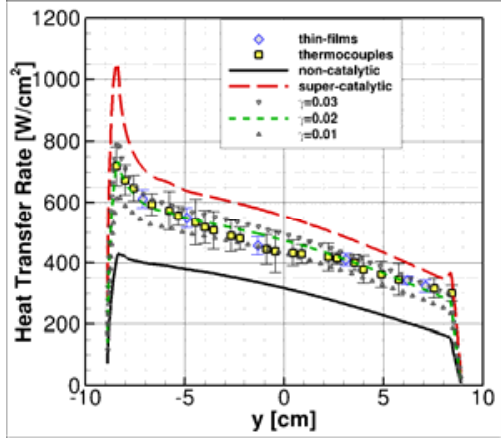

(f) Run 13

Figure 13. Comparison of Measured and Predicted Surface Heat Flux for All Runs

\section{E. Numerical Uncertainty}

Per the AIAA standard on numerical uncertainty,[36] several forms of error in CFD solutions are considered. Since all the simulations were performed for laminar flows on grids aligned to the shock, DPLR converged close to machine precision limits in all cases (about 14 orders of magnitude residual decrease). Spatial grid dependency is considered more fully since it is the primary verification error mode for the simulations. To address this, the baseline grid (after shock alignment) was increased in density from the nominal $1.6 \times 10^{6}$ cells for the Run 03 solution for the SRE catalytic wall with $\gamma=0.02$. This particular solution was picked since Run 03 was repeated once and was one of the highest enthalpy conditions. The $\gamma=0.02$ solution appears to match the experimental data most closely among the wall models tested. Unfortunately, computer memory limitations made it impossible to double the grid density, so the grid density was increased by $50 \%$ in each direction (through linear interpolation along the nominal grid lines) to form a fine grid level with $5.4 \times 10^{6}$ cells. This fine grid was then sequenced by two in each direction to provide a coarse grid, yielding three grid levels with relative cell density of 1.5, 1.0, and 0.75 . Since heat transfer is the most sensitive metric for blunt body stagnation regions, the heat transfer was compared for the Run 03 SRE $\gamma=0.02$ case between all three grids across the locations where the experimental measurements are compared. The percent difference between the finest grid level and the nominal and coarse grids are shown in Fig. 14. The percent difference varies from location to location on the surface, but is within $1.1 \%$ between the finest and nominal grids. The coarse solution is slightly larger. 


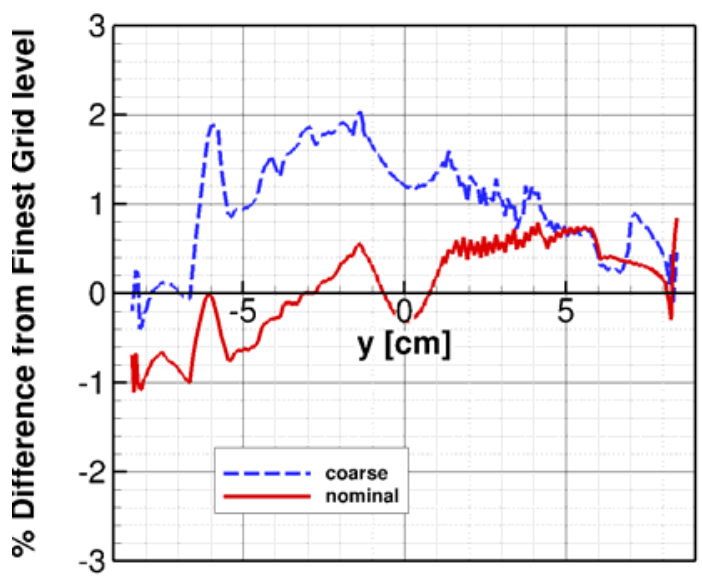

Figure 14. Percent Difference of Heat Flux from Fine Grid Level along Geometric Centerplane

This percent difference can be interpreted as a Richardson extrapolation error estimator $\left(E_{1}\right)$ if the spatial order of accuracy is known.[37] The DPLR code is formally second order, but the use of limiters through the bow shock can reduce the observed order of accuracy to something between 1.0 and 2.0. If we assume that, at worst, the method will converge as first order, the $\mathrm{E}_{1}$ error estimator from the finest grid level is equal to the percent difference divided by the ratio of cell densities minus one. Because the percent difference varies from point to point on the surface, the average, median, minimum, and maximum percent difference values for each grid have been extracted as representative metrics. These error estimator values are summarized in Table II.

Extracting the observed order of accuracy from the three grid solutions proved to be erratic largely because the nominal solution is adapted to the bow shock, but the fine and coarse grid solutions are derived from the nominal grid. As these additional grids were not re-adapted to the bow shock independently, the percent differences between the solutions may equally be caused by grid adaptation differences rather than formal convergence accuracy. In any event, the values summarized in Table II should represent conservative estimates of grid convergence and demonstrate that the nominal grid is sufficiently resolved to within approximately $3 \%$ or less. This level of grid convergence is more than sufficient to make accurate comparisons to the experimental measurements.

\begin{tabular}{|c|c|c|c|c|}
\hline Grid level & mean & $\begin{array}{l}\text { Accuracy } \\
\text { median }\end{array}$ & minimum & maximum \\
\hline nominal & $0.006 \%$ & $0.3 \%$ & $1.7 \%$ & $-2.2 \%$ \\
\hline coarse & $1.5 \%$ & $1.1 \%$ & $2.0 \%$ & $-0.4 \%$ \\
\hline
\end{tabular}

Validation of the numerical models carries far larger uncertainty than the spatial or temporal convergence of the numerical methods in this application. Heat flux is measured directly in the experiment, but the computed heat flux is dependent on a number of assumed physical models such as gas phase reaction rates, vibrational relaxation, electronic excitation, viscosity, thermal conductivity, diffusion, and catalytic reaction efficiencies. The true uncertainty in many of these models is largely unknown - indeed the characterization and reduction of such uncertainties is the primary purpose of the experiments.

\section{F. Non-Dimensional Analysis}

A non-dimensional analysis was completed based on the Stanton number (Ch)-Reynolds (Re) number scaling typical used in lower enthalpy shock tunnel programs. Where noted, a reference temperature correction based on the estimated boundary layer temperature from Cheng [38] was used to compute $\mathrm{Ch}^{*}$ and $\mathrm{Re}^{*}$ values. Figure $15 \mathrm{a}$ shows the non-dimensional heat transfer for all run as a reference, but normalizing these data yields a more interesting result. Figure 15b attempts to collapse all run data with the reference temperature correction, and the authors find it very interesting that indeed all of these program runs do collapse so well. It is not obvious, at this point, if the reference temperature correction is physically meaningful across this large range of conditions involving complex shock layer chemistry, or if it is a fortuitous result related to some other phenomenon, but is indicating results are consistent and this is a positive result. Figure 16 is the same as Fig. 15b with two additional LENS I runs included from the hot shoulder program (67CH).[39] LENS I Run 18 was at $5 \mathrm{MJ} / \mathrm{kg}$, and this run appears to collapse well 
with the current program data. LENS I Run 14, however, was at approximately $10 \mathrm{MJ} / \mathrm{kg}$ and significant freestream dissociation exists at this enthalpy level. Interestingly, this run does not collapse well with the current dataset at all. In addition to the reference temperature correction, LENS I heat transfer rates were scaled up based on the ratio of the square root of the diameters of the models used. The LENS I model had a $14 \mathrm{in}$. diameter, so a factor of root two was applied to its non-dimensional data. Again, it is not clear what should happen, and there are not enough runs at high enthalpies at this point to provide a clear non-dimensional analysis, but there are certainly some interesting questions raised. Future work will improve the understanding of non-dimensional analyses at these very high enthalpies.

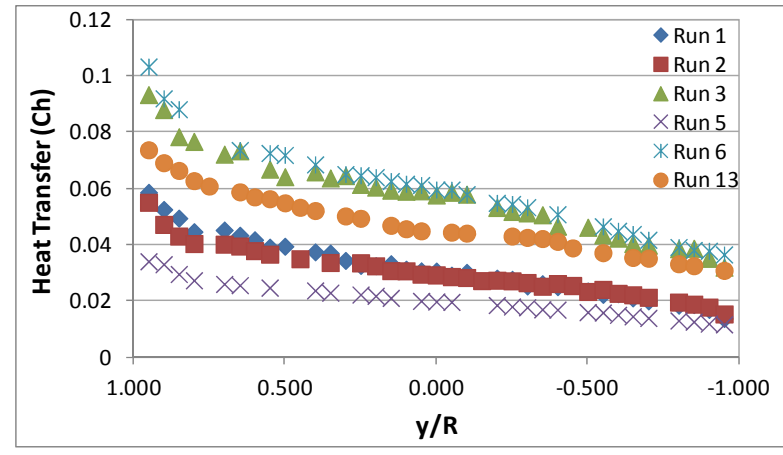

(a) Non-Dimensional Heat Transfer

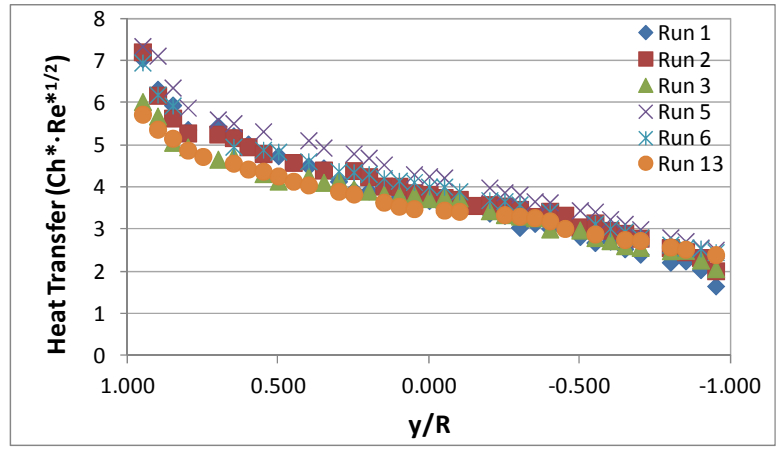

(b) Non-Dimensional Heat Transfer with Reference Temperature Correction Normalized with Reynolds Number Based on Laminar Boundary Layer Exponent

Figure 15. Heat Transfer vs. Position for LENS-XX Runs

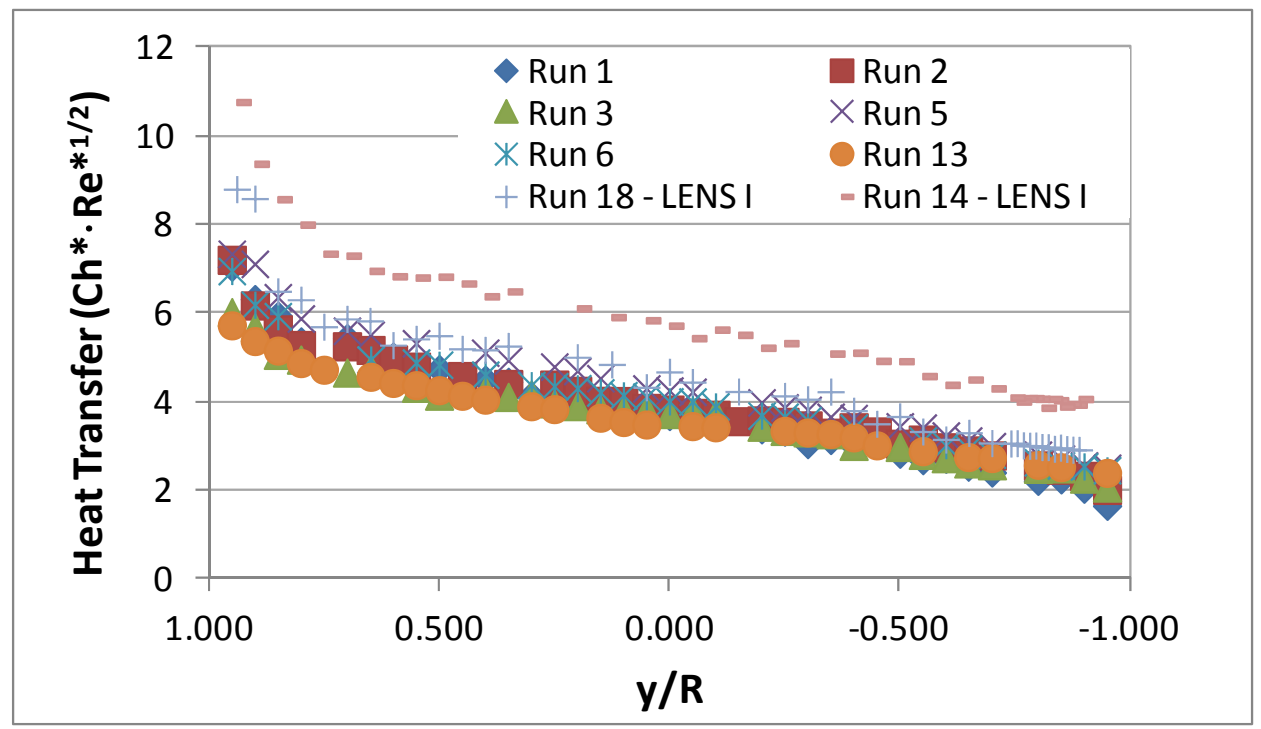

Figure 16. Non-Dimensional Heat Transfer with Reference Temperature Correction Normalized with Reynolds Number Based on Laminar Boundary Layer Exponent vs. Position for LENS-XX Runs Including Two Moderate Enthalpy 67CH LENS I Runs 


\section{Conclusions}

A comprehensive heat transfer dataset was collected in an expansion tunnel in high enthalpy flows up to $36 \mathrm{MJ} / \mathrm{kg}$ with a non-dissociated freestream. A major finding of this test series is that the low-density flows displayed surface heating behavior that is observed to be consistent with some finite-rate recombination process occurring on the surface of the model. It is too early to speculate on the nature of the mechanism, but the response of the gages on the surface seems generally repeatable and consistent for a range of conditions. This result is an important milestone in developing and proving a capability to make measurements in a ground test environment and extrapolate them to flight for conditions with extreme non-equilibrium effects. In general, no significant, isolated stagnation point augmentation ("bump") was observed in the tests in this facility. Cases at higher Reynolds number seemed to show the greatest amount of overall increase in heating on the windward side of the model, which may in part be due to small-scale particulate; in general, however, the surface heating data trends were very well behaved.

\section{Acknowledgements}

CUBRC would like to thank NASA Johnson Space Center for their support of this unique work under contracts W31P4Q-04-C-R095 and NNJ11373914R.

\section{References}

1. $\quad$ Dufrene, A., Sharma, M., and Austin, J. M. "Design and Characterization of a Hypervelocity Expansion Tube Facility," Journal of Propulsion and Power Vol. 23, 2007, pp. 1185-93.

2. Dufrene, A., MacLean, M., Parker, R. A., and Holden, M. S. "Experimental Characterization of the LENS Expansion Tunnel Facility Including Blunt Body Surface Heating," 49th AIAA Aerospace Sciences Meeting. Orlando, FL, AIAA Paper 2011-626, 2011.

3. Dufrene, A., MacLean, M., Parker, R. A., Wadhams, T. P., and Holden, M. S. "Characterization of the New LENS Expansion Tunnel Facility," 48th AIAA Aerospace Sciences Meeting. Orlando, FL, AIAA Paper 2010-1564, 2010.

4. MacLean, M., Dufrene, A., Wadhams, T. P., and Holden, M. S. "Numerical and Experimental Characterization of High Enthalpy Flow in an Expansion Tunnel Facility," 48th AIAA Aerospace Sciences Meeting. Orlando, FL, AIAA Paper 2010-1562, 2010.

5. Trimpi, R. L. "Preliminary theoretical study of expansion tube, new device for producing high-enthalpy short-duration hypersonic gas flows." NASA TR R-133, 1962.

6. $\quad$ Erdos, J., Bakos, R., and Castrogiovanni, A. "Dual Mode Shock-Expansion/Reflected-Shock Tunne," 35th Aerospace Sciences Meeting. Reno, NV, AIAA Paper 97-0560, 1997.

7. Jacobs, P. A., Silvester, T. B., Morgan, R. G., Scott, M. P., Gollan, R. J., and McIntyre, T. J. "Superorbital Expansion Tube Operation: Estimates of Flow Conditions via Numerical Simulation," 43rd Aerospace Sciences Meeting. Reno, NV, AIAA Paper 2005-0694, 2005.

8. Sharma, S., and Park, C. "Operating Characteristics of a 60- and 10-cm Electric Arc-Driven Shock Tube - Part I: The Driver," Journal of Thermophysics and Heat Transfer Vol. 4, No. 3, 1990, pp. 259-265.

9. $\quad$ Wright, M. J., Candler, G. V., and Bose, D. "Data-parallel line relaxation method for the Navier-Stokes equations," AIAA Journal Vol. 36, No. Copyright 1998, IEE, 1998, pp. 1603-9.

10. MacCormack, R. W., and Candler, G. V. "The solution of the Navier-Stokes equations using Gauss-Seidel line relaxation," Symposium on Physical Aspects of Numerical Gas Dynamics, 12-13 Aug. 1987. 1 ed. Vol. 17, UK, 1989, pp. 135-50.

11. Park, C. Nonequilibrium Hypersonic Aerothermodynamics. New York: Wiley, 1990.

12. Bose, D., and Candler, G. V. "Thermal Rate Constants of the N2 + O -> NO + N. Reaction Using ab initio ZA" and 3A' Potential Energy Surfaces," Journal of Chemical Physics Vol. 107, No. 8, 1996, pp. 2825-2833.

13. Bose, D., and Candler, G. V. "Thermal Rate Constants of the O2 + N --> NO + O Reaction Based on the 2A'and 4A' Potential-Energy Surfaces," Journal of Chemical Physics Vol. 107, No. 8, 1997, pp. 6136-6145.

14. Candler, G. V. "Chemistry of External Flows Aerothermochemistry for Hypersonic Technology: Von Karman Institute for Fluid Dynamics Lecture Series," Aerothermochemistry for Hypersonic Technology: Von Karman Institute for Fluid Dynamics Lecture Series., VKI LS 1995-04.

15. Landau, L., and Teller, E. "Theory of Sound Dispersion," Physikalische Zeitschrift der Sowjetunion Vol. 10, No. 34, 1936.

16. Millikan, R., and White, D. "Systematics of Vibrational Relaxation," Journal of Chemical Physics Vol. 39, No. 12, 1963, pp. 3209-3213.

17. Camac, M. "CO2 Relaxation Processes in Shock Waves," Fundamental Phenomena in Hypersonic Flow, 1964, pp. 195-215.

18. Park, C., Howe, J. T., Jaffe, R. J., and Candler, G. V. "Review of Chemical-Kinetic Problems of Future NASA Missions II: Mars Entries," Journal of Thermophysics and Heat Transfer Vol. 8, No. 1, 1994, pp. 9-23.

19. Park, C. "Assessment of Two-temperature Kinetic Model for Ionizing Air," 22nd AIAA Thermophysics Conference. Honolulu, HI, AIAA Paper 87-1574, 1987. 
20. Marrone, P. V., and Treanor, C. E. "Chemical Relaxation with Preferential Dissociation from Excited Vibrational Levels," The Physics of Fluids Vol. 6, No. 9, 1963, pp. 1215-1221.

21. Palmer, G. E., and Wright, M. J. "A Comparison of Methods to Compute High Temperature Gas Viscosity," Journal of Thermophysics and Heat Transfer Vol. 17, No. 2, 2003, pp. 232-239.

22. Palmer, G. E., and Wright, M. J. "A Comparison of Methods to Compute High Temperature Gas Thermal Conductivity," 36th AIAA Thermophysics Conference. Orlando, FL, AIAA Paper 2003-3913, 2003.

23. Gupta, R., Yos, J., Thompson, R., and Lee, K. "A Review of Reaction Rates and Thermodynamic and Transport Properties for an 11-Species Air Model for Chemical and Thermal Nonequilibrium Calculations to 30000 K." NASA RP-1232, 1990.

24. Wright, M. J., Bose, D., Palmer, G. E., and Levin, E. " Recommended Collision Integrals for Transport Property Computations, Part 1: Air Species," AIAA Journal Vol. 43, No. 12, 2005, pp. 2558-2564.

25. Ramshaw, J. D. "Self-consistent Effective Binary Diffusion in Multicomponent Gas Mixtures," Journal of NonEquilibrium Thermodynamics Vol. 15, No. 3, 1990, pp. 295-300.

26. Baldwin, B. S., and Lomax, H. "Thin Layer Approximation and Algebraic Model for Separated Turbulent Flows," 16th Aerospace Sciences Meeting, Huntsville, AL. AIAA Paper 78-0257, 1978.

27. Spalart, P. R., and Allmaras, S. R. "A One-Equation Turbulence Model for Aerodynamic Flows," 30th Aerospace Sciences Meeting \& Exhibit, Reno, NV. AIAA Paper 92-0439, 1992.

28. Menter, F. R. "Two-equation eddy-viscosity turbulence models for engineering applications," AIAA Journal Vol. 32, No. Compendex, 1994, pp. 1598-1605.

29. Brown, J. "Turbulence Model Validation for Hypersonic Flows," 8TH Thermophysics and Heat Transfer Conference, St. Paul, MN. AIAA Paper 2002-3308, 2002.

30. Catris, S., and Aupoix, B. "Improved Turbulence Models for Compressible Boundary Layers," 2nd Theoretical Fluid Mechanics Meeting, Albuquerque, NM. AIAA Paper 98-2696, 1998.

31. MacLean, M., Marschall, J., and Driver, D. "Finite-Rate Surface Chemistry Model, II: Coupling to Viscous NavierStokes Code," 42ND Thermophysics Conference. Honolulu, HI, AIAA Paper 2011-3784, 2011.

32. Marschall, J., and MacLean, M. "Finite-Rate Surface Chemistry Model, I: Formulation and Reaction System Examples," 42ND Thermophysics Conference. Honolulu, HI, AIAA Paper 2011-3783, 2011.

33. MacLean, M., and Holden, M. S. "Numerical Assessment of Data in Catalytic and Transitional Flows for Martian Entry," 9TH AIAA/ASME Joint Thermophysics and Heat Transfer Conference. San Francisco, CA, AIAA Paper 20062946, 2006.

34. MacLean, M., Mundy, E., Wadhams, T. P., Holden, M. S., and Parker, R. A. "Analysis and Ground Test of Aerothermal Effects on Spherical Capsule Geometries," 38th Fluid Dynamics Conferencr. Seattle, WA, AIAA Paper 2008-4273 2008.

35. MacLean, M., Marineau, E. C., Parker, R. P., Dufrene, A., Holden, M. S., and DesJardin, P. "Effect of Surface Catalysis on Measured Heat Transfer in an Expansion Tunnel Facility," 50th AIAA Aerospace Sciences Meeting. Nashville, TN, 2012.

36. American Institute of Aeronautics and Astronautics. Guide for the Verification and Validation of Computational Fluid Dynamics Simulations: AIAA G-077-1998, 1998.

37. Roy, C. J. "Grid Convergence Error Analysis for Mixed-Order Numerical Schemes," AIAA Journal Vol. 41, No. 4, 2003, pp. 595-604.

38. Cheng, H. K., Hall, J. G., Golian, T. C., and Hertzberg, A. "Boundary Layer Displacement and Leading-Edge Bluntness Effects in High-Temperature Hypersonic Flow," Journal of the Aerospace Sciences Vol. 28, No. 5, 1961, pp. 353-381.

39. Wadhams, T. P., MacLean, M., and Holden, M. S. "Experimental Studies of the Aerothermal Characteristics of the Project Orion CEV Heat Shield in High Speed Transitional and Turbulent Flows," 47th AIAA Aerospace Sciences Meeting. Orlando, FL, AIAA Paper 2009-677, 2009. 